\title{
Evaluation of the prevalence of broad-spectrum beta-lactamases (ESBLs) and carbapenemase genes in Klebsiella pneumoniae strains isolated from burn wounds in patients referred to Shahid Motahari Hospital in Tehran
}

\author{
Ali Shivaee ${ }^{1}, \underline{\text { Shahla Shahbazi }}{ }^{2}$, Armaghan Soltani ${ }^{3}$, Elaheh Ahadi $^{4}$ \\ ${ }^{I}$ MSc in Medical Microbiology, Department of Microbiology, School of Medicine, Iran University of Medical Sciences, \\ Tehran, Iran \\ ${ }^{2}$ PhD Student, Department of Bacteriology, Pasteur Institute of Iran, Teheran, Iran \\ ${ }^{3}$ MSc Student in Microbiology, Department of Bacteriology, Pasteur Institute of Iran, Teheran, Iran \\ ${ }^{4}$ MSc Student in Microbiology, Department of Biology, Alborz Branch, Islamic Azad University, Karaj, Iran
}

\begin{abstract}
Background: Klebsiella species are common causes of nosocomial, ulcers, blood and urinary tract infections, and also acquired pneumonia from the hospital and various intra-abdominal infections. Bacterial resistance mechanisms against antibiotics are different, but one of these resistance mechanisms, which is very problematic, is the production of $\beta$-lactamase enzymes in bacteria. The aim of this study was to determine the antibiotic resistance pattern and the presence of beta-lactamase genes in Klebsiella isolated from burn wounds among patients referred to Shahid Motahhari Hospital in Tehran.

Materials and methods: 100 strains collected for confirmation of production of broad-spectrum betalactamases (ESBLs) were tested by CDT (Combined Disk Test). Finally, $\beta$-lactamase genes were investigated using polymerase chain reaction.

Results: The highest resistance rate was observed to ampicillin (93\%). 23\% of isolates produced ESBLs. The highest frequency of genes was bla shv gene (26.8\%).

Conclusion: The presence of beta-lactamase genes with high antibiotic resistance is very worrying. Since the present genes can spread through mobile genetic elements in bacteria, among bacteria, it is considered to be a serious alert in the treatment of infections caused by Klebsiella.

Keywords: Klebsiella pneumoniae, Antibiotic resistance, Beta-lactamase genes, ESBLs.
\end{abstract}

Cited as: Shivaee A, Shahbazi SH, soltani A, Ahadi E. Evaluation of the prevalence of broad-spectrum beta-lactamases (ESBLs) and carbapenemase genes in Klebsiella pneumoniae strains isolated from burn wounds in patients referred to Shahid Motahari Hospital in Tehran. Medical Science Journal of Islamic Azad University, Tehran Medical Branch 2019; 29(3): 232-239.

Correspondence to: Shahla Shahbazi

Tel: +98 89910179127

E-mail: shahbazi.shahla@yahoo.com

ORCID ID: 0000-0001-5189-9974

Received: 20 Aug 2018; Accepted: 25 Nov 2018 
مجله علوم يزشكى دانشگاه آزاد اسلامى

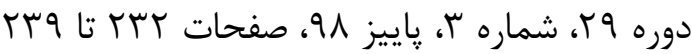

\title{
بررسى ميزان شيوع زنهاى كد كننده بتالاكتاماز وسيع الطيف (ESBLS) و
}

\section{كاربإنماز در سويههاى كلبسيلا بنومونيه جدا شده از زخمهاى سوختى سنى بيماران مر اجعه كننده به بيمارستان شهيد مطهرى تهران}

\author{
على شيوايى'، شهلا شهبازى'، ارمغان سلطانى"، الهه احدى"
}

'كارشناسى ارشد ميكروب شناسى، دانشكده يزشكى، دانشكاه علوم بز شكى ايران، تهر ان، ايران

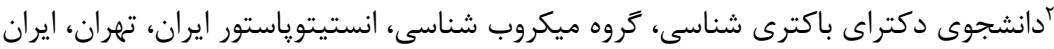

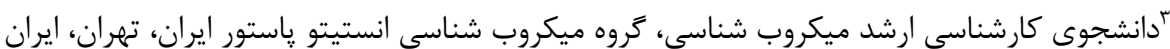

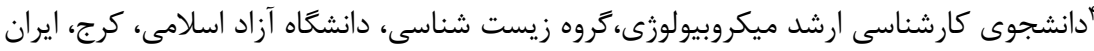

جكيده

سابقه و هدف. باكترى جنسهاى كلبسيلا /زعوامل شايع عفونتهاى بيمارستانى، زخمه، عفونت مجارى ادرارى، عفونت خون، بنومونى اكتسابى

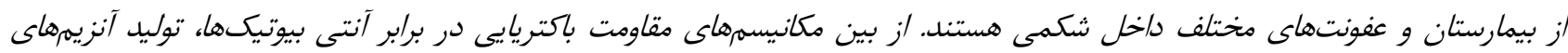

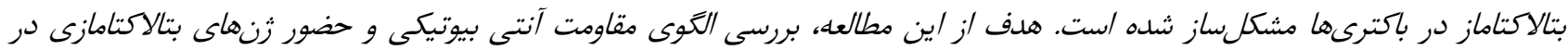

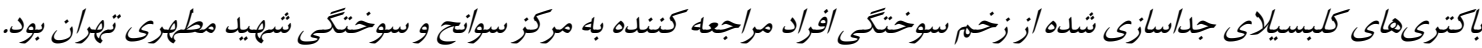

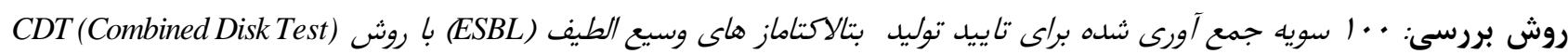

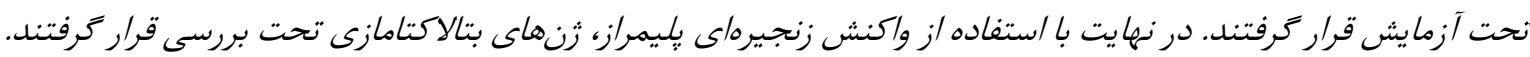

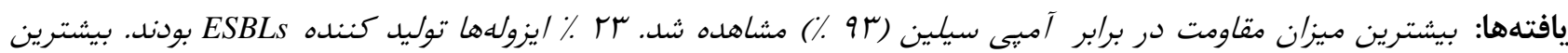

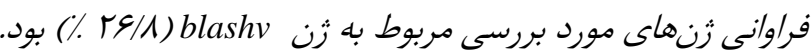

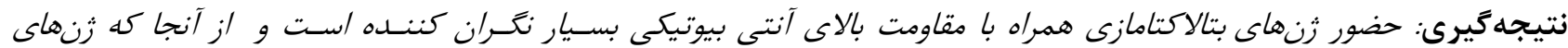

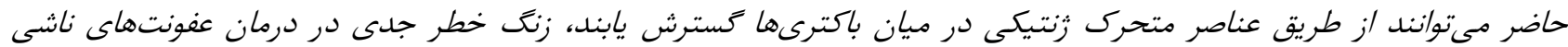
از كلبسيلا محسوب مىشوند. وازَّان كليدى: كلبسيلا بنومونيه، مقاومت آنتى بيوتيكى، زن هاى بتالاكتامازى، ESBLs.

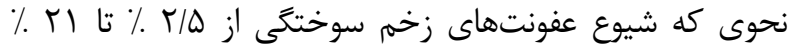

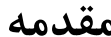
متغير است (ז, ؟َ). براساس مطالعات بزرى انجام شده در ايران

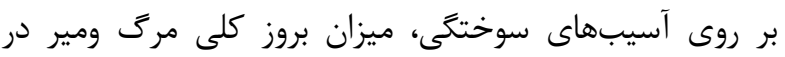

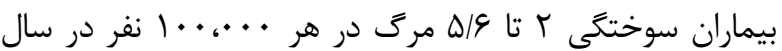
است (1). از جمله راهكارهاى درمانى براى مقابله با اين عفونتها

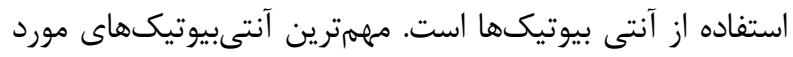

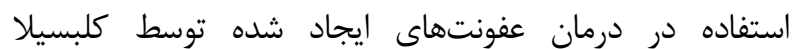

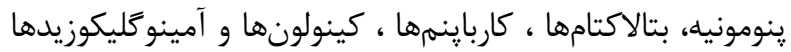
همان طوركه تحقيقات در كشورهاى مختلف نشان داده، كلبسيلا

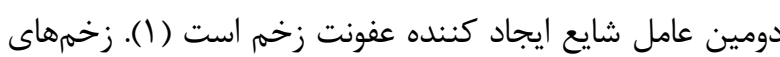
سوختگى يكى از عمدهترين شرايط مستعد به عفونت است، به إسه 


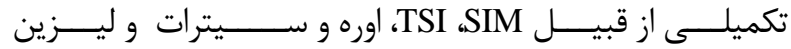
دكربوكسيلاز براى تاييد اين نمونه ها انجـام شـد. يـس از تعيـين

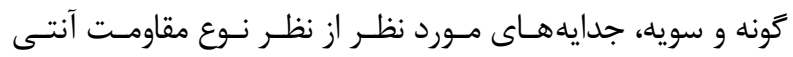

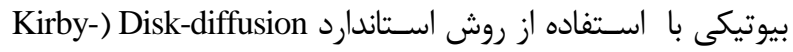

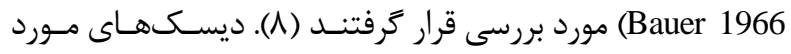
استفاده در اين مطالعه (Mast Co., UK) شامل آميى سـيلين (Bg)

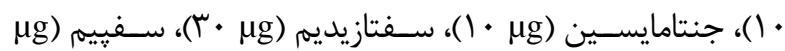

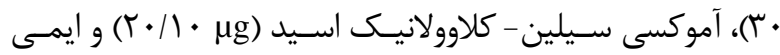

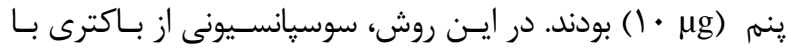

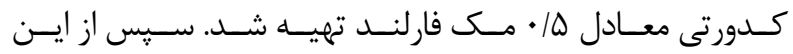

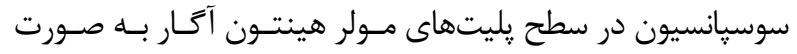
كشت انجام شد و ديسك ها در سطح يليـتهــا قـرار

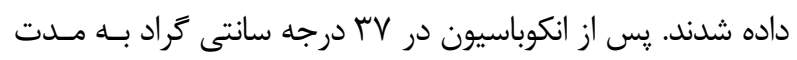

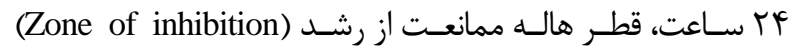
برحسب ميلى متر با استفاده از خط كش اندازه گيرى شد و نتـايج

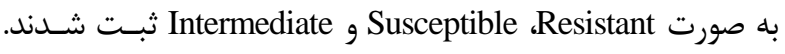

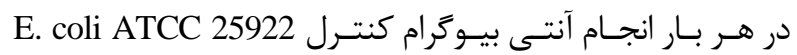
استفاده شد.

بــه منظـور شناسايـى باكترى هــاى توليدكنــده ESBLs، در ابتـدا

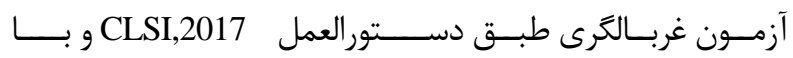
اسـتفاده از ديــسك آنتى بيوتيكهاى سفوتاكسـيم، سـفتازيديم،

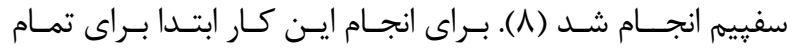

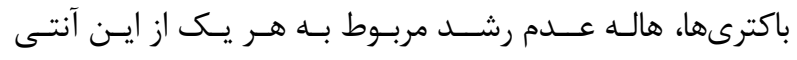

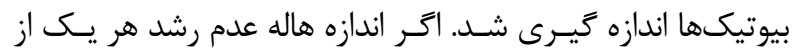
اين آنتى بيوتيكها براى سويه ها مطابق جدول ا بود، تستهـاى تأييدى براى آنها انجـام شـد.

جدول ا. معيارهاى غربالكرى جهـت شناسـايى اركانيسـم هـاى مولـد NCCLS بر اساس دستورالعمل ESBL

\begin{tabular}{|c|c|}
\hline قطر هاله عدم رشد(mm) & آنتى بيوتيك \\
\hline$r r \leq$ & سفتازيديم \\
\hline$T V \leq$ & سفوتاكسيم \\
\hline$r \Delta \leq$ & سفييم \\
\hline
\end{tabular}

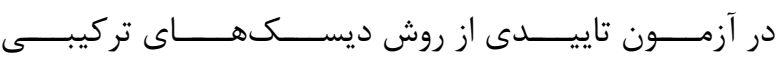
استفاده شد. براى اين منظــور (Combination Disk Method)

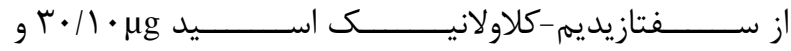

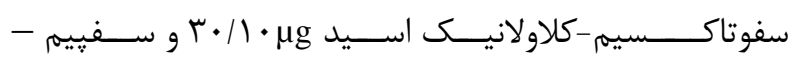

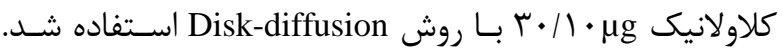
افزايشmm ه ه كقطر هاله ديسكهاى تركيبى يا كلاولانيك
و كوتريماكسازول هستند. به دليل ايجاد مقاومت آنتى بيوتيكى در طول درمان عفونتهاى ايجاد شده توسط كلبسيلا ينومونيه، استفاده صحيح آنتىبيوتيكى بسيار مرهم است (f). مكانيسمهاى مقاومت باكتريايى در برابر آنتى بيوتيكها متفاوت است، اما يكى بـى از اين مكانيسمهاى مقاومتى كه بسيار مشكل ساز شده است،

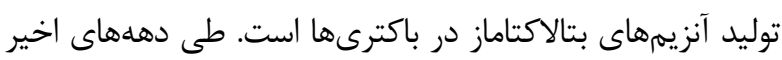

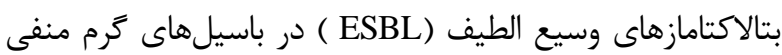
يافت شده است و به عنوان مكانيسم مهرم مقاومت محسوب مىشوند. آنزيمهاى ESBL قادر به هيدروليز ينى سيلينها،

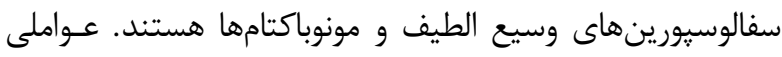
همجون كلاولونيك اسيد، تازوباكتام و سولباكتام با اثر

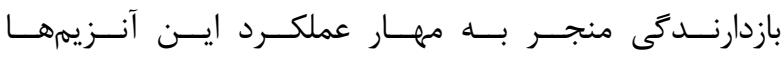

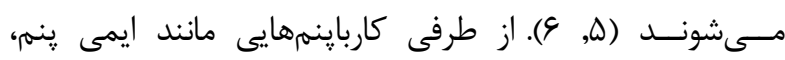

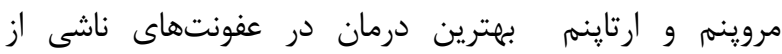
باكترىهاى مولد بتالاكتاماز هاى وسيع الطيف هستند. اما متاسفانه با افزايش استفاده از اين آنتى بيوتيكها شمار

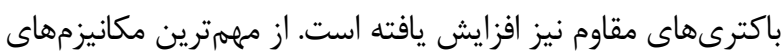
مقاومتى عليه كارباينهم توليد كاربإنماز است كه KPC و VIM از

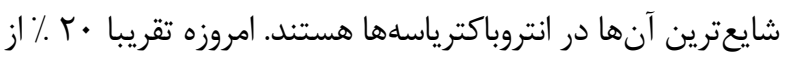
عفونتهاى كلبسيلاينومونيه در بخشهاى مراقبت ويزه در ايالات متحده شامل سويههاى غير حساس به نسل سوم سفالوسيورينها است كه علت اصلى اين امر كسب يلاسميدهاى حاوى زنهاى

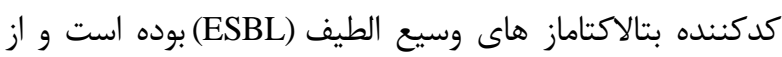
آنجايى كه اين يلاسميدها اغلب حامل زن هاى مقاومت ديخرى مانند زنهاى كاربإِنمازى نيز هستند (V)، درمان عفونتهاى جدى اعضاى انتروباكترياسه توليدكننده ESBL، نيازمند توجه

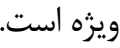

لذا با توجه به افزايش روبه رشد اين سويههاى ESBL و كارباينمازها و اهميت زخمهاى سوختگى در كلينيكها، مطالعه حاضر به منظور بررسى وجود زنهاى كد كننده بتالاكتاماز وسيع الطيف (ESBLs) و كارباينماز در سويههاى كلبسيلا ينومونيه جدا شده از زخم هاى سوختخى بيماران مراجعه كننده به بيمارستان شهيد مطهرى تهران انجام شد.

\section{مواد و روشهها}

دراين مطالعه توصـيفى -مقطعى (cross-sectional)، تعـداد .

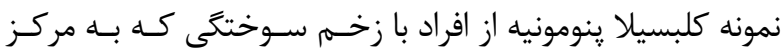

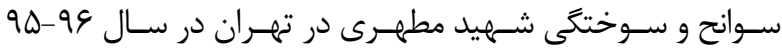

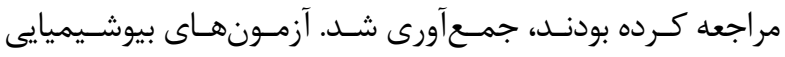




\begin{tabular}{|c|c|c|c|c|}
\hline يرايمر & توالى يرايمر ('3 جا'5) & اندازه محصول (bp) & 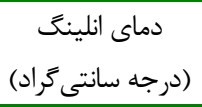 & ر رفرنس \\
\hline bla SHV & $\begin{array}{l}\text { F: ATGCGTTATATTCGCCTGTG } \\
\text { R:TGCTTTGTTATTCGGGCCAA }\end{array}$ & $V F V$ & $\Delta F$ & (9) \\
\hline bla TEM & $\begin{array}{c}\text { F:TCGCCGCATACACTATTCTCAGAATGA } \\
\text { R:ACGCTCACCGGCTCCAGATTTAT }\end{array}$ & $\Delta F \Delta$ & c. & (9) \\
\hline bla CTX-M & $\begin{array}{l}\text { F:ATGTGCAGYACCAGTAARGTKATGGC } \\
\text { R:TGGGTRAARTARGTSACCAGAAYCAGGG }\end{array}$ & pq & $\Delta \Lambda$ & (9) \\
\hline bla VEB & $\begin{array}{l}\text { F: GCGTTATGAAATTTCCGATTG } \\
\text { R: CAACATCATTAGTGGCTGCTG }\end{array}$ & אוז & $\Delta F$ & $(1 \cdot)$ \\
\hline bla GES & $\begin{array}{l}\text { F: ATGCGCTTCATTCACGCAC } \\
\text { R: CTATTTGTCCGTGCTCAGG }\end{array}$ & red & $\Delta \Delta$ & $(1 \cdot)$ \\
\hline bla PER & $\begin{array}{l}\text { F: GCCTGACGATCTGGAACC } \\
\text { R: GATACTGCACCTGATCATC }\end{array}$ & $1 \wedge$. & $\Delta \Delta$ & $(1 \cdot)$ \\
\hline bla OXA & $\begin{array}{l}\text { F: CTGTTGTTTGGGTTTCGCAAG } \\
\text { R: CTTGGCTTTTATGCTTGATG }\end{array}$ & $9 \Delta V$ & Dr & $(1 \cdot)$ \\
\hline bla KPC & $\begin{array}{l}\text { F: ATGTCACTGTATCGCCGTCTAGT } \\
\text { R: CGTTGACGCCCAATCC }\end{array}$ & $\wedge \vee$. & $\Delta \varphi$ & (11) \\
\hline
\end{tabular}

F: forward; R: reverse

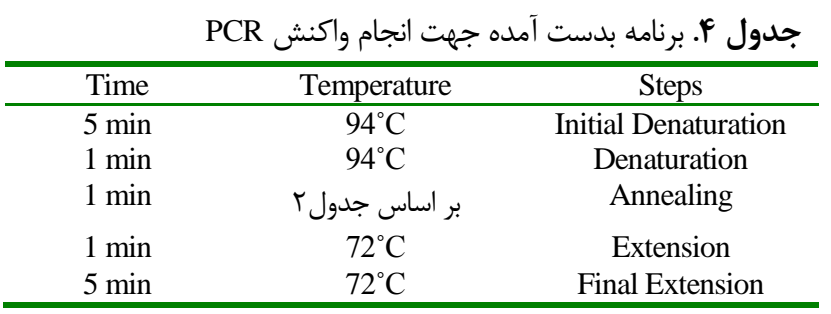

يس از انجام PCR بر روى DNA حاصل از نمونهها، محصولات

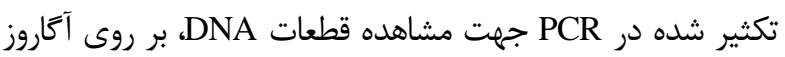

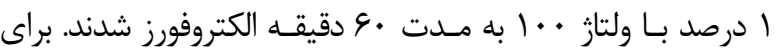
مشاهده و تصويربردارى محصولات PCR الكتروفورز شده در زل ادرات مربوطه از سيستم Gel documentation استفاده شد. در نهايت بال استفاده از DNA الكَو كه حاوى قطعاتى بـا وزن مولكولى مشخص است، محصول شناسـايى شد.

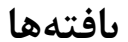

تمامى .. نمونه كلبسيلا پينومونيه از نظر تست اكسـيداز و وتوليــ كـاز سـولفيد هيـدروزن مثبت، تست ليزين دكربوكسيلاز، اوره آز، انسدول و حركت منفـى هيد، اما سيترات مثبت بودند و قادر بودند در محسيط مك كانكى در دماى آلى

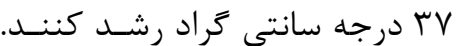
نتايج حاصل از تست آنتى بيوكرام به روش كربى - بـائر

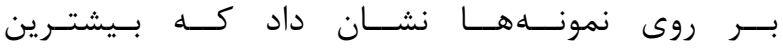

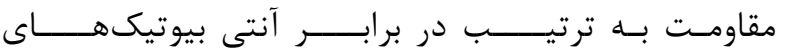
آميى سيلين (بو درصد) و آموكسى سيلين كلاولانيك برابـ اسيد (rاه درصد) و بيشتــرين حساسيت به ترتيـب در درئ
اسيد نسبت به ديسكهاى فاقد اين آنتى بيوتيك نشان دهنده

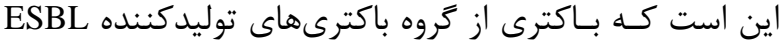

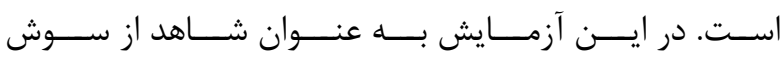

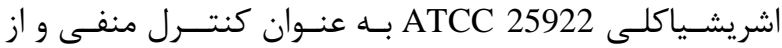

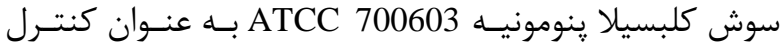

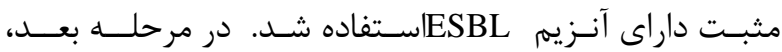
DNA رنوميك با استفاده از كيت استخراج DNA DNA ) و يروتكل همراه با كيت استخراج شد.

جدول r. مقادير و موارد به كار رفته جهت تهيه مخلوط واكنش PCR

\begin{tabular}{rr}
\hline PCR Mixture Components & Volume \\
\hline PCR Buffer $(10 \mathrm{X})$ & $2.5 \mu \mathrm{l}$ \\
MgCl2 $(25 \mathrm{mM})$ & $1-2 \mu \mathrm{l}$ \\
$\mathrm{dNTPs}(10 \mathrm{mM})$ & $1 \mu \mathrm{l}$ \\
Primer Forward $(10 \mathrm{pmol} / \mu \mathrm{l})$ & $1 \mu \mathrm{l}$ \\
Primer Reverse $(10 \mathrm{pmol} / \mu \mathrm{l})$ & $1 \mu \mathrm{l}$ \\
Taq DNA Polymerase $(5 \mathrm{U} / \mu \mathrm{l})$ & $0.1 \mu \mathrm{l}$ \\
Template DNA & Variable \\
ddH2O & Variable \\
Total volume & $25 \mu \mathrm{l}$ \\
\hline
\end{tabular}

به منظور تكثير زنهاى بتالاكتامازى VTA ، CTX-M TEM SHV، MPC و OXA PER GES يرايمرها از مقالات موجود استخراج و پس از Bast كردن در يايخاه دادهها NCBI و حصول اطمينان از مناسب بودن آنها، انتخاب شدند.

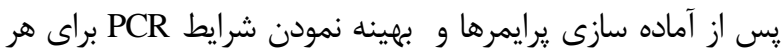

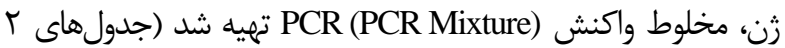

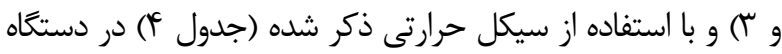
ترموسايكلر (Eppendorf) تكثير اين رنها انجام كرفت 


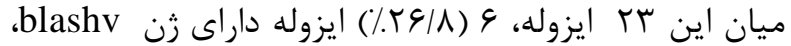

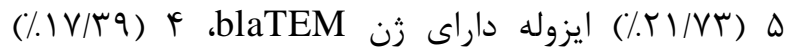

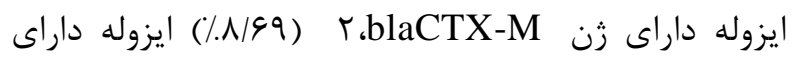

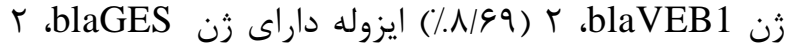

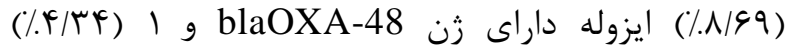

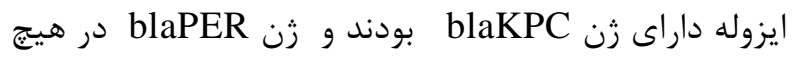

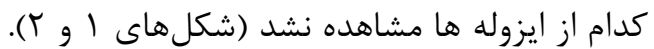

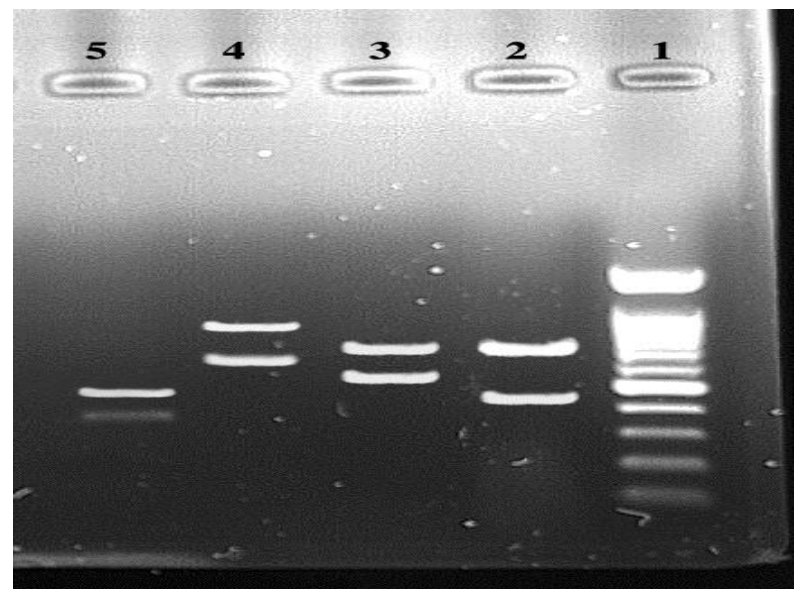

شكل r. نتايج مالتى يلكسPCR زنهاى توليد كننده ESBL بر .

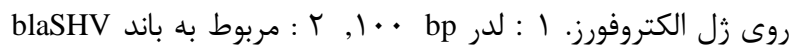

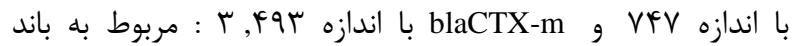

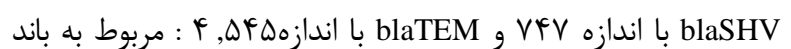

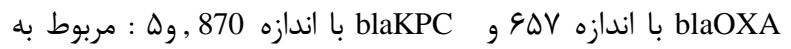

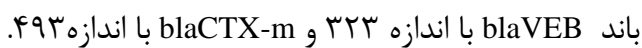

بحث

خسترش توليد آنزيمهاى بتالاكتاماز وسيع الطيف يكى از خطرهاى جدى در درمان عفونتهاى داراى مقاومت جندائ

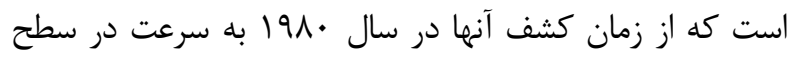
جهان گَترش يافتهاند و به عنوان يكى از معضلات بهداشت عمومى خود را نمايان ساخته است. شيوع ESBL در بين كونههاى بالينى از يك كشور به كشور ديخر و از يك مؤسسه تا

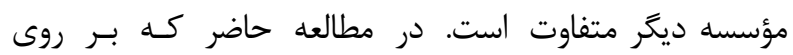
ايزولـههاى كلبسيلا ينومونيه جــدا شده از زخم سوختكى افراد مراجعه كننده به مركز سوانح و سوختگى شهيد مطهرى در تهران

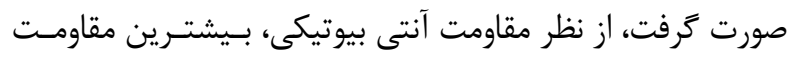

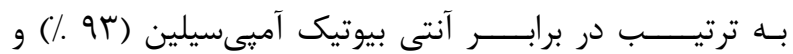

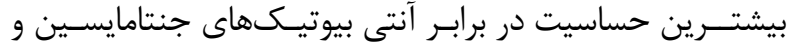

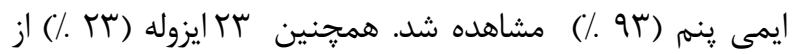
كـل نمونـهـا ESBL مثبت بودند. مطالعات مشابه زيادى در ايران
برابـر آنتى بيوتيـكهاى جنتامايسـين و ايمى ينهم (1) درصد) و سفتازيديم (•1 درصد) بود (جدول ه). نتايج به اله

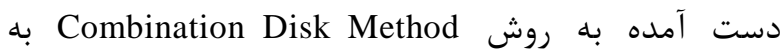
منظور تعيين سويههاى توليد كننده ESBL نشان داد كه r ايزوله از مجموع • إ ايزوله ESBL مثبت هستند.

\begin{tabular}{|c|c|c|c|c|}
\hline \multicolumn{5}{|c|}{ كلبسيلا ينومونيه (تعداد: · () } \\
\hline 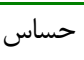 & نيمه حساس & 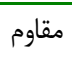 & $(\mu \mathrm{g} / \mathrm{disc})$ & \\
\hline$(/)$. & (/.) & (/.) & & آنتى بيوتيك \\
\hline$\cdot$ & v & 9 & $1 \cdot$ & آميى سيلين \\
\hline q & v & · & $1 \cdot$ & جنتاميسين \\
\hline$\wedge \cdot$ & • & $r \cdot$ & $r \cdot$ & سفتازيديم \\
\hline$\wedge \cdot$ & $\cdot$ & $r \cdot$ & $r$. & سفييم \\
\hline v & f. & $\Delta r$ & $r \cdot / l$. & آموكسى سيلين - \\
\hline & & & & كلاولانيك اسيد \\
\hline $9 \pi$ & $\cdot$ & v & $\Delta$ & ايمى ينه \\
\hline
\end{tabular}

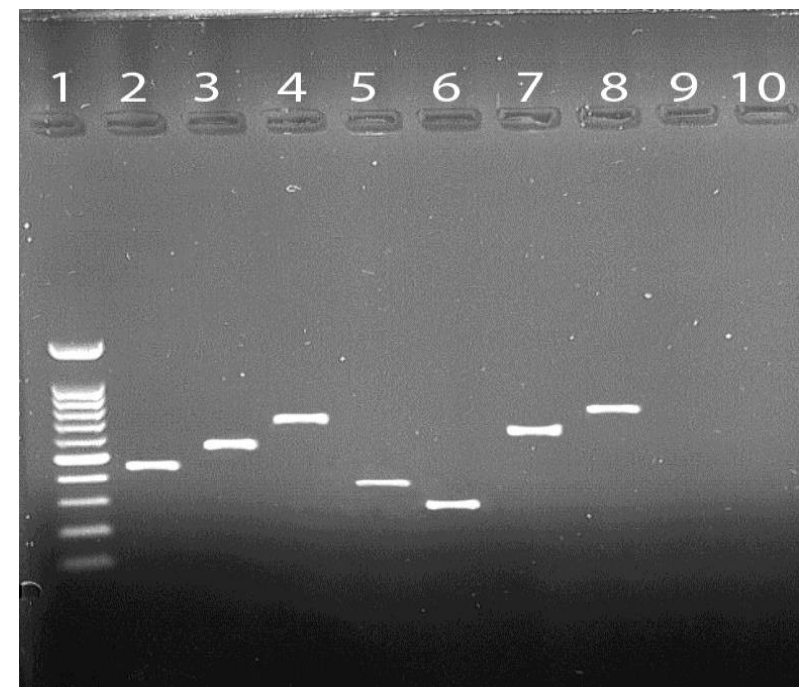

شكل ا. عكس مربوط به زن هاى توليد كننده ESBL بر روى زل

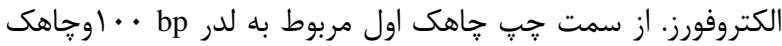

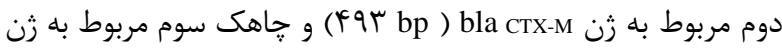

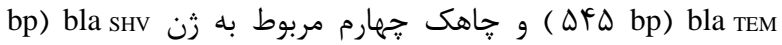

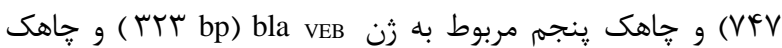

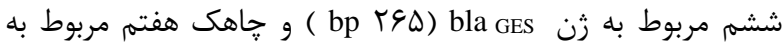

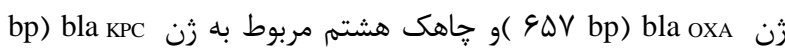

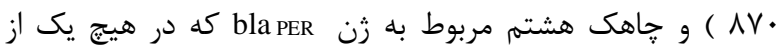

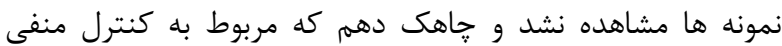
است.

بر روى بr ايزولهاى كه از نظر فنوتييى توليد كننده آنزيمهاى بتالاكتاماز بودند، آزمايش 
كرد كه در اين مطالعه تعدادى از آنها از جمله blaVEB1، blaPER و blaKPC blaOXA-48 blaGES

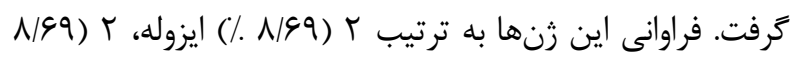

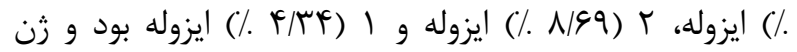
blaPER در هيج كدام از ايزولهها مشاهده نشد. در مطالعهاى كه آندا

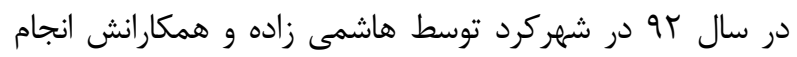

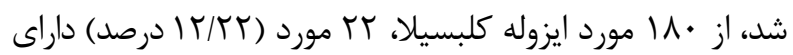
زن blaKPC بودند (IV) (IV). در مقايسه مطالعه حاضر با مطالعه Bratu

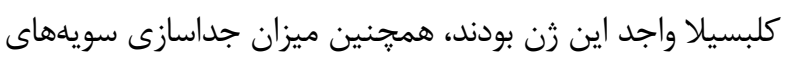
كلبسيلا واجد زن blaKPC در اين مطالعه خيلى كمتر از مطالعه Castanheira

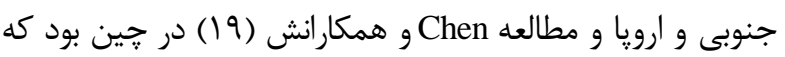

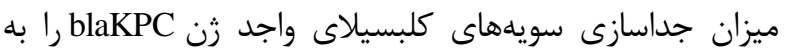

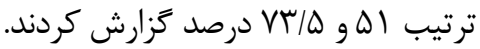

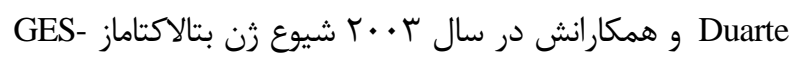
1 را در باكترى كلبسيلا ينومونيه در بيمارستان دانشخاه شهر ليسبون يرتغال مورد بررسى قرار دادند و در مطالعه آنها تمامى داني

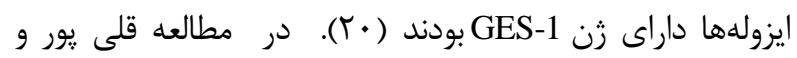

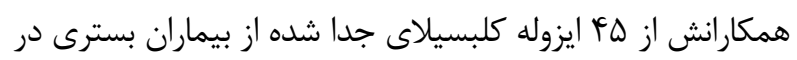

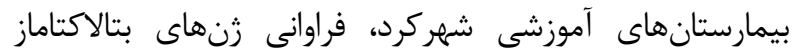

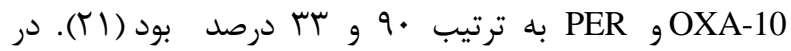

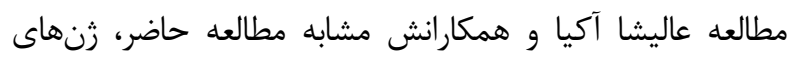

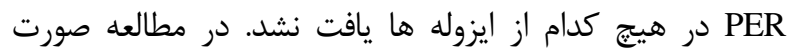

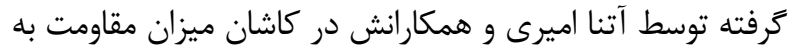

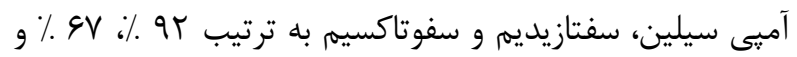

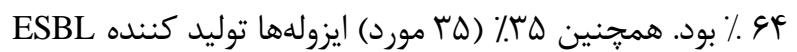

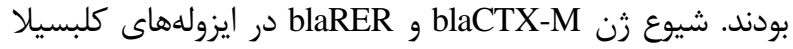

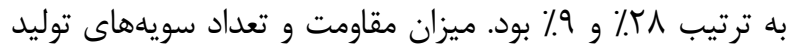

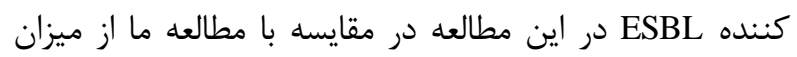

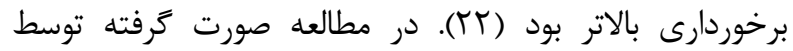
Pattarachai Kiratisin

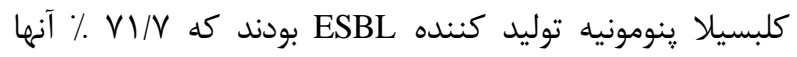

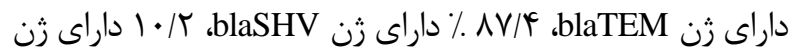

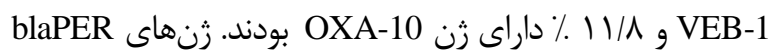

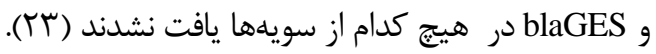
بررسى و مقايسه نتايج مطالعه حاضر با مطالعه ساير محققان

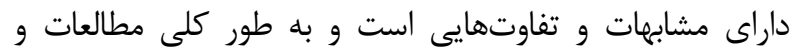
كزارشهاى متعددى در خصوص افزايش و شيوع رو رو به رائ رشد اركانيسمهاى مولد ESBLs از مناطق مختلف در كشور وجود دارد
و ساير نقاط جهان در زمينه كلبسيلا ينومونيه توليد كننده ESBLs صورت كرفته توسط فيض آبادى و همكارانش در تهران در سال

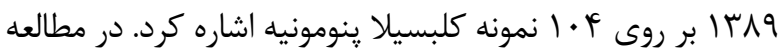

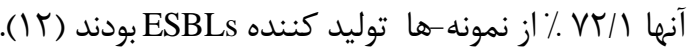

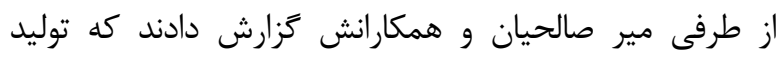
ESBLs

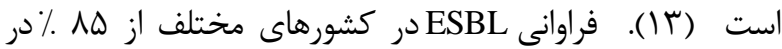

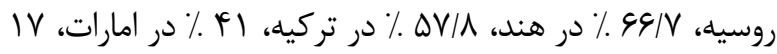

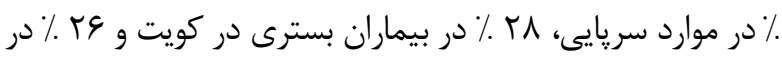

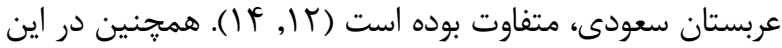
مطالعه فراوانى زنهـاى بتالاكتامسازى TEM و CTX و

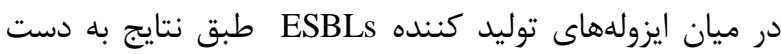

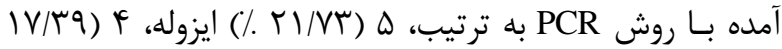

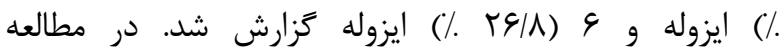

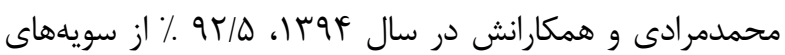
كلبسيلا ينومونيه نسبت به آنتى بيوتيك آميى سييلين مقاوم بودند كه مشابه نتيجه حاصل از مطالعه حاضر بود. ميزان حساسيت به آنتى بيوتيك جنتامايسين تقريبا بالاى •9.

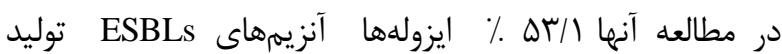

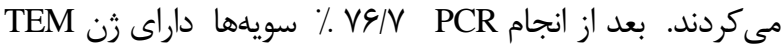

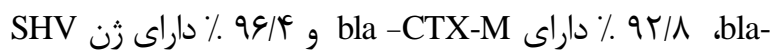

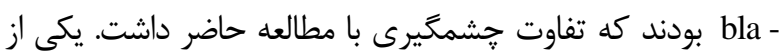

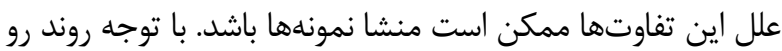
به افزايش مقاومت آنتى بيوتيكى در كلبسيلا ينومونيه، امروزه كارباينمها به عنوان خط نهايى درمانى استفاده مي دشوند، اما ديا

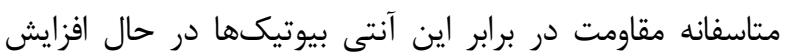
است كه اين براى عفونتهاى بيمارستانى بسيار نكران كننده

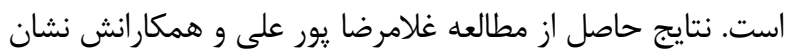

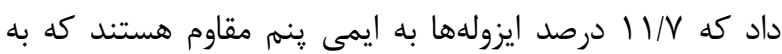
عنوان دارويى كه به عنوان آخرين خط درمانى جهت عفونت

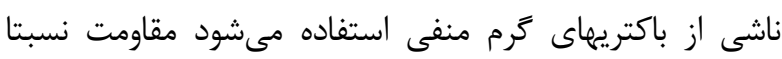

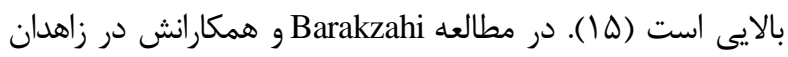

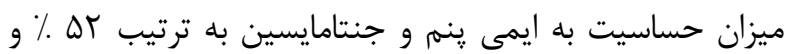

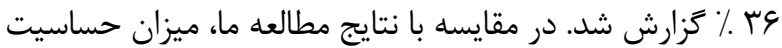

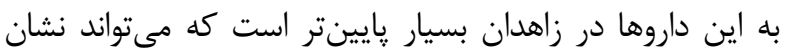

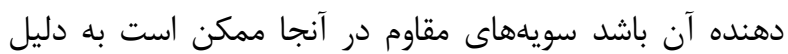
رفت و آمد بسيار مهاجران از كشورهاى همسايه وارد شده باشند

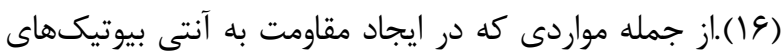

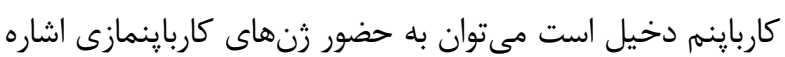




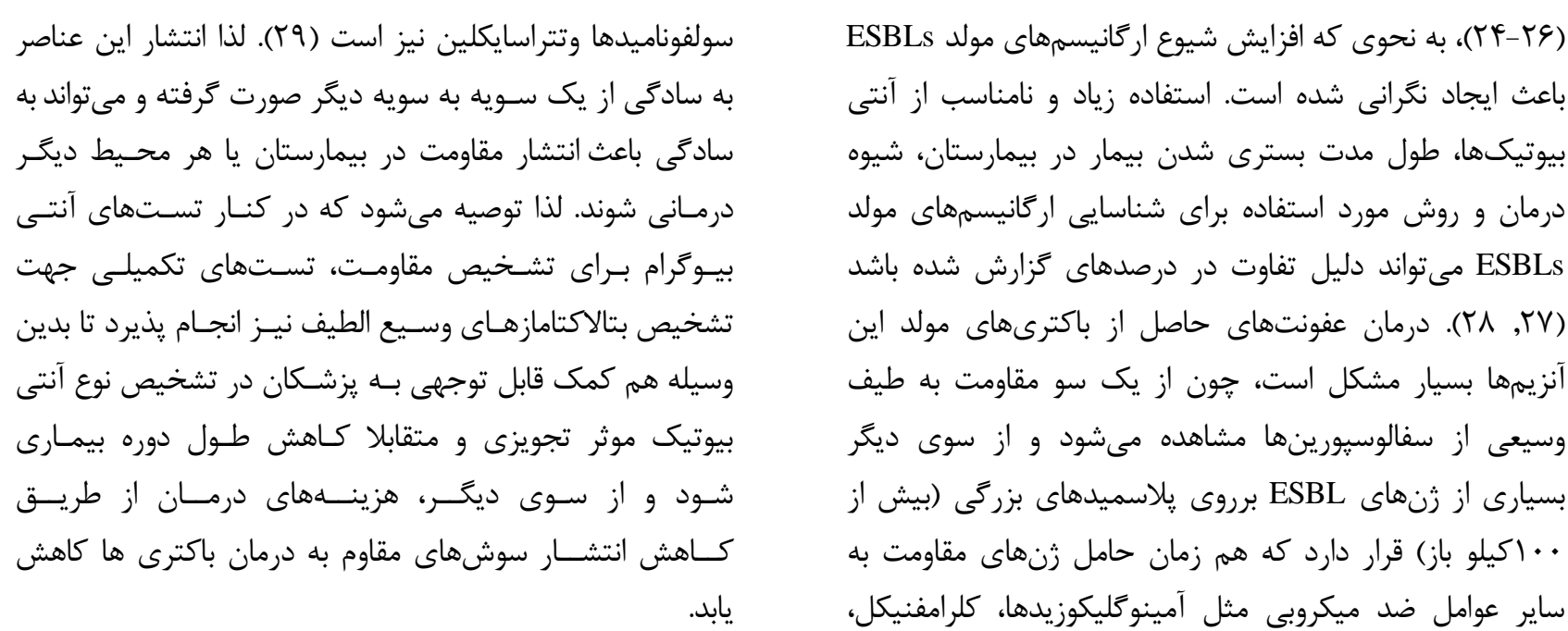

\section{REFERENCES}

1. Afkhamzadeh A, Majidi F, Ahmadi C. Risk factors for nosocomial infections among burn patients hospitalized in Tohid hospital, Sanandaj, Kurdistan Iran. Medical Journal of Mashhad University of Medical Sciences 2016;59:225-32. [In Persian]

2. Groohi B, Alaghehbandan R, Lari AR. Analysis of 1089 burn patients in province of Kurdistan, Iran. Burns 2002;28:569-74.

3. Askarian M, Vakili M, Kabir G. Results of a hospital waste survey in private hospitals in Fars province, Iran. Waste Manag 2004;24:347-52.

4. Pfeifer Y, Cullik A, Witte W. Resistance to cephalosporins and carbapenems in Gram-negative bacterial pathogens. Int J Med Microbiol 2010;300:371-9.

5. Nasehi L, Shahcheraghi F, Nikbin VS, Nematzadeh S. PER, CTX-M, TEM and SHV Beta-lactamases in clinical isolates of Klebsiella pneumoniae isolated from Tehran, Iran. Iranian Journal of Basic Medical Sciences 2010;13:111-8.

6. Ayan M, Durmaz R, Aktas E, Durmaz B. Bacteriological, clinical and epidemiological characteristics of hospitalacquired Acinetobacter baumannii infection in a teaching hospital. J Hosp Infect 2003;54:39-45.

7. Paterson DL. Resistance in gram-negative bacteria: Enterobacteriaceae. Am J Med 2006;34:S20-S8.

8. Reller LB, Weinstein M, Jorgensen JH, Ferraro MJ. Antimicrobial susceptibility testing: a review of general principles and contemporary practices. Clin Infect Dis 2009;49:1749-55.

9. Monstein HJ, Ostholm-Balkhed A, Nilsson MV, Nilsson M, Dornbusch K, Nilsson LE. Multiplex PCR amplification assay for the detection of blaSHV, blaTEM and blaCTX-M genes in Enterobacteriaceae. APMIS 2007;115:1400-8.

10. Zhou CC, Irani RA, Zhang Y, Blackwell SC, Mi T, Wen J, et al. Angiotensin receptor agonistic autoantibodymediated tumor necrosis factor- $\alpha$ induction contributes to increased soluble endoglin production in preeclampsia. Circulation 2010;12:436-44.

11. Eftekhar F, Naseh Z. Extended-spectrum $\beta$-lactamase and carbapenemase production among burn and non-burn clinical isolates of Klebsiella pneumoniae. Iran J Microbiol 2015;7:144.

12. Feizabadi MM, Mahamadi-Yeganeh S, Mirsalehian A, Mirafshar S-M, Mahboobi M, Nili F, et al. Genetic characterization of ESBL producing strains of Klebsiella pneumoniae from Tehran hospitals. J Infect Dev Ctries 2010;4:609-15.

13. Decré D, Gachot B, Lucet JC, Arlet G, Bergogne-Bérézin E, Régnier B. Clinical and bacteriologic epidemiology of extended-spectrum beta-lactamase-producing strains of Klebsiella pneumoniae in a medical intensive care unit. Clin Infect Dis 1998;27:834-44.

14. Hussain A, Mirza IA, Ikra A, Sattar A, Ali S, Khan IU. In vitro sensitivity of chloramphenicol against extended spectrum beta lactamase producing gram negative bacteria. Infectious Diseases Journal of Pakistan 2012;4:503.

15. Monstein HJ, Ostholm-Balkhed A, Nilsson MV, Nilsson M, Dornbusch K, Nilsson LE. Multiplex PCR amplification assay for the detection of blaSHV, blaTEM and blaCTX-M genes in Enterobacteriaceae. APMIS 2007;115:1400-8. 
16. Barakzahi M, Hormozi B, Rashki A, Ghalehnoo ZR. Prevalence of extended spectrum $\beta$-Lactamase in Klebsiella pneumonia isolates in a teaching hospital of Zahedan City, Iran. Avicenna Journal of Clinical Microbiology and Infection 2014;1:e22934.

17. Mirnejhad R, Hashemizadeh FS, Zamanzad B, Jahandideh S, Ansari N, Gholipour A, et al. Identification of KPCproducing Klebsiella pneumoniae in clinical samples in Iran. Yafte Journal of Medical Sciences 2013;15:105-14. [In Persian]

18. Castanheira M, Sader HS, Deshpande LM, Fritsche TR, Jones RN. Antimicrobial activities of tigecycline and other broad-spectrum antimicrobials tested against serine carbapenemase-and metallo- $\beta$-lactamase-producing Enterobacteriaceae: report from the SENTRY Antimicrobial Surveillance Program. Antimicrob Agents Chemother 2008;52:570-3.

19. Chen S, Hu F, Xu X, Liu Y, Wu W, Zhu D, et al. High prevalence of KPC-2-type carbapenemase coupled with CTX-M-type extended-spectrum $\beta$-lactamases in carbapenem-resistant Klebsiella pneumoniae in a teaching hospital in China. Antimicrob Agents Chemother 2011;55:2493-4.

20. Duarte A, Boavida F, Grosso F, Correia M, Lito L, Cristino JM, et al. Outbreak of GES-1 $\beta$-lactamase-producing multidrug-resistant Klebsiella pneumoniae in a university hospital in Lisbon, Portugal. Antimicrob Agents Chemother 2003;47:1481-2.

21. Latifpour M, Gholipour A, Damavandi M S. The study of antibiotic resistance of extended-spectrum betalactamase-producing Klebsiella strains isolated from urinary tract infections in teaching Hospitals in Shahrekord . J Shahrekord Univ Med Sci 2016; 18:45-53. [In Persian]

22. Amiri A, Firoozeh F, Moniri R, Zibaei M. Prevalence of CTX-M-type and PER extended-spectrum $\beta$-lactamases among Klebsiella spp. isolated from clinical specimens in the Teaching Hospital of Kashan, Iran. Iranian Red Cres Med J 2016;18:e22260. [In Persian]

23. Kiratisin P, Apisarnthanarak A, Laesripa C, Saifon P. Molecular characterization and epidemiology of extendedspectrum- $\beta$-lactamase-producing Escherichia coli and Klebsiella pneumoniae isolates causing health care-associated infection in Thailand, where the CTX-M family is endemic. Antimicrob Agents Chemother 2008;52:2818-24

24. Mansouri S, Neyestanaki DK, Shokoohi M, Halimi S, Beigverdi R, Rezagholezadeh F, et al. Characterization of AmpC, CTX-M and MBLs types of $\beta$-lactamases in clinical isolates of Klebsiella pneumoniae and Escherichia coli producing Extended Spectrum $\beta$-lactamases in Kerman, Iran. Jundishapur J Microbiol 2014;7:e8756.

25. Moghaddam MN, Beidokhti MH, Jamehdar SA, Ghahraman M. Genetic properties of blaCTX-M and blaPER $\beta$ lactamase genes in clinical isolates of Enterobacteriaceae by polymerase chain reaction. Iranian Journal of Basic Medical Sciences 2014;17:378.

26. Ghasemi Y, Archin T, Kargar M, Mohkam M. A simple multiplex PCR for assessing prevalence of extendedspectrum $\beta$-lactamases producing Klebsiella pneumoniae in Intensive Care Units of a referral hospital in Shiraz, Iran. Asian Pac J Trop Med 2013;6:703-8.

27. Franiczek R, Dolna I, Krzyzanowska B, Szufnarowski K, Kowalska-Krochmal B. Conjugative transfer of multiresistance plasmids from ESBL-positive Escherichia coli and Klebsiella spp. clinical isolates to Escherichia coli strain K12 C600. Adv Clin Exp Med 2007;16:239.

28. Bali EB, Accedil L, Sultan N. Phenotypic and molecular characterization of SHV, TEM, CTX-M and extendedspectrum-lactamase produced by Escherichia coli, Acinobacter baumannii and Klebsiella isolates in a Turkish hospital. African J Microbiol Res 2010;4:650-4.

29. Stürenburg E, Mack D. Extended-spectrum $\beta$-lactamases: implications for the clinical microbiology laboratory, therapy, and infection control. J Inf 2003;47:273-95. 